\title{
THE POSSIBILITIES OF EARLY FAULT DETECTION OF ENGINES
}

\author{
Jan Filipczyk \\ Silesian University of Technology, Faculty of Transport \\ Krasinskiego Street 8, 40-019 Katowice, Poland \\ e-mail: jan.filipczyk@polsl.pl
}

\begin{abstract}
The paper presents the results of investigation of damage causes in internal combustion engines. The investigation has been carried out in 2000-2012 at the Department of Motor Vehicles Maintenance at The Faculty of Transport - The Silesian University of Technology. The study has been conducted by analysing of the failure causes of diesel and spark ignition engines and the possibilities of diagnosing the technical condition of the engines in order to detect faults in the early stages. Traditional methods such as compression test, the measurement of harmful substances in the exhaust gases as well as analysis of signals from the on-board diagnostic systems, analysis of acoustic signals have been used to diagnose technical state of engines. The results of diagnostic tests have been verified during operation of engines and repairs which were carried out. The study was conducted for 628 engines. The faults, which were not detected at the early stage, caused a complete brake down of engines in 63 cases. The causes of engine faults can be classified as follows: those ones due to normal wear during operation, maintenance errors, damages of lubrication and cooling systems, faults of injection and timing systems, manufacturing defects. A high percentage of faulty engines with low mileage shows that early diagnosis of damages is extremely important. The faults of electronic control system, ignition timing and engine management malfunction may be the reason of a complete destruction of the engine.
\end{abstract}

Keywords: fault diagnosis, faults of engine

\section{Introduction}

This study has been a result of failure investigations related to spark and diesel engine failures which occurred during vehicle tests, carried out in 2000-2012. Studies have been conducted within the framework of research on the changing technical conditions of different category of vehicles, operating in various conditions and their ability to diagnose the faults $[1,2]$. The analysis of causes of engine damages have been the main goal of many studies. Types of engine damages have been classified as fatigue and excessive or normal wear of particular parts, faults connected with electrical system and control units, faults of fuel system due to the poor fuel quality, etc. The fatigue of engine parts has been classified as mechanical and high temperature mechanical, as well as thermal and thermal-mechanical [3]. The main causes of thermo-mechanical fatigue damages have been classified as a thermo-mechanical overload by insufficient intercooling and thermomechanical overload by over-fuelling [4]. The types of piston and cylinder damages have been classified as seizure due to insufficient clearances, seizure due to poor lubrication, seizure due to overheating, damages due to abnormal combustion, piston and piston ring fractures, piston pin fractures, damage to the piston pin circlips, seizures in the piston pin bores, piston noises, increased oil consumption due to excessive wear on pistons, piston rings and cylinder running surfaces [4-6]. The causes of turbocharger faults can be classified as oil starvation, oil contamination, foreign object damage and normal wear and tear [7].

\section{Diagnostic methods of investigation}

A number of diagnostic systems for automotive engines maintenance and repair have been developed in recent years. These systems are employed for diagnosing variety of faults in the engine and are available at service level. The measurements of electrical quantities varying according to the 
wear of particular parts of engines, acoustic signal, concentration of compounds in the exhaust gas in a single stoke cycle as well as signals from on-board diagnostic system can give important information about the technical condition of engines. Diagnostic signals can provide information about the engine failure at the early stage and also the type of damage. Scheme of engine as a diagnostic model has been shown in Fig. 1. Information about the technical state of the engine can be the results of the analysis of changes in the inlet mass flow, the signals coming from the residual processes, the stream of the dissipated energy and the energy changes at the output of the systems.

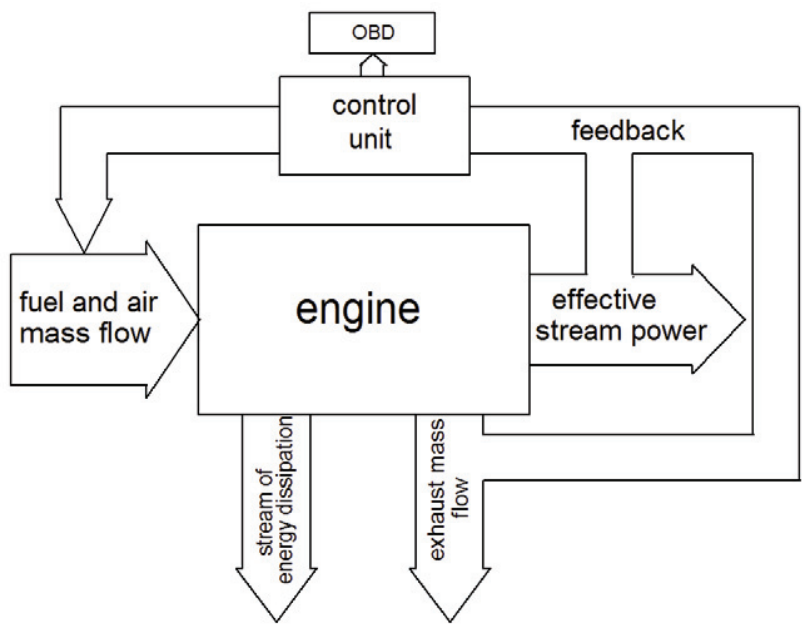

Fig. 1. Scheme of diagnostic model of engine

Preliminary test focused on the engine fuel consumption, measurement of exhaust gases and analysis of OBD signals. Engines in passenger cars were additionally tested on the roller dynamometer stand. In the second step test program included measurements of acoustic signals within the head, cylinder block, crankcase, valve - gear mechanism, water pump, fuel injection pump and turbocharger, measuring the current intensity drawn by the starter, compression test and endoscopy of the cylinder. Damaged engine components were verified during repairs.

\section{Checking faults of automotive engines}

The type of faults and the possibilities of early diagnosis were the main goal of engine examinations. The investigations have been conducted in authorized service stations. The investigations have been carried out at two stages. The first stage concentrated on the analysis of 628 cases of faulty engines. The structure of engine types which was examined has been presented in Fig. 2.

The value of overhaul lifetime and the impact of faults on technical state of the engine have been determined for each case. The diagnostics of engine using OBD system has been carried out where it was possible.

The second stage concentrated on the analysis of the type and causes of engine faults, which had damaged pistons and cylinders, turbochargers and valves. The analysis was carried out for 63 completely broken-down engines.

\section{Causes of engine damages}

During the examinations of faulty working engines, $21.8 \%$ were connected with faulty electric control system. This type of faults caused the damage of pistons, cylinders or valves in many cases. Malfunction of the control system, which caused mechanical damages of piston, was recognized using OBD tests in only 12 cases. Piston and cylinder damages were recognized during endoscopy, as a result of faulty control system in $56 \%$ of cases. The structure of engine faults has been presented in Fig 3. 


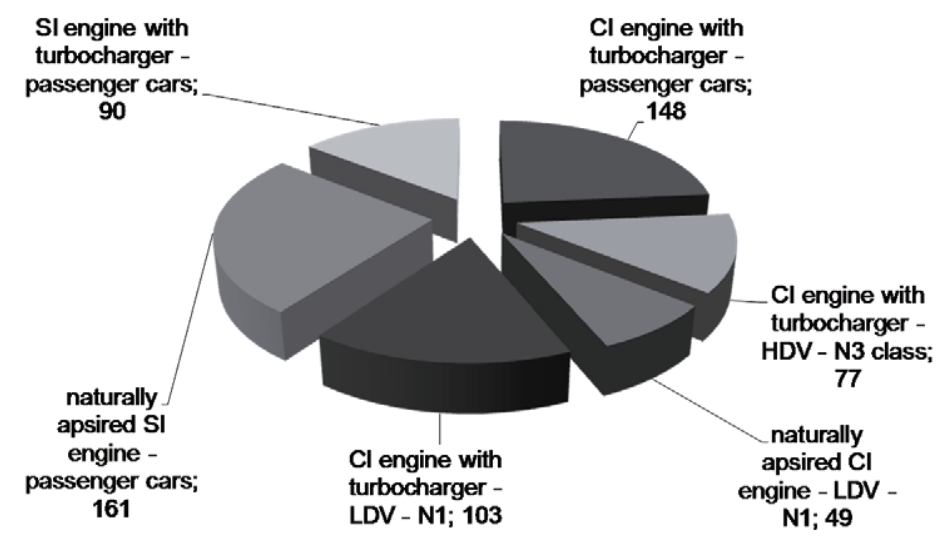

Fig. 2. Structure of engine types which was examined

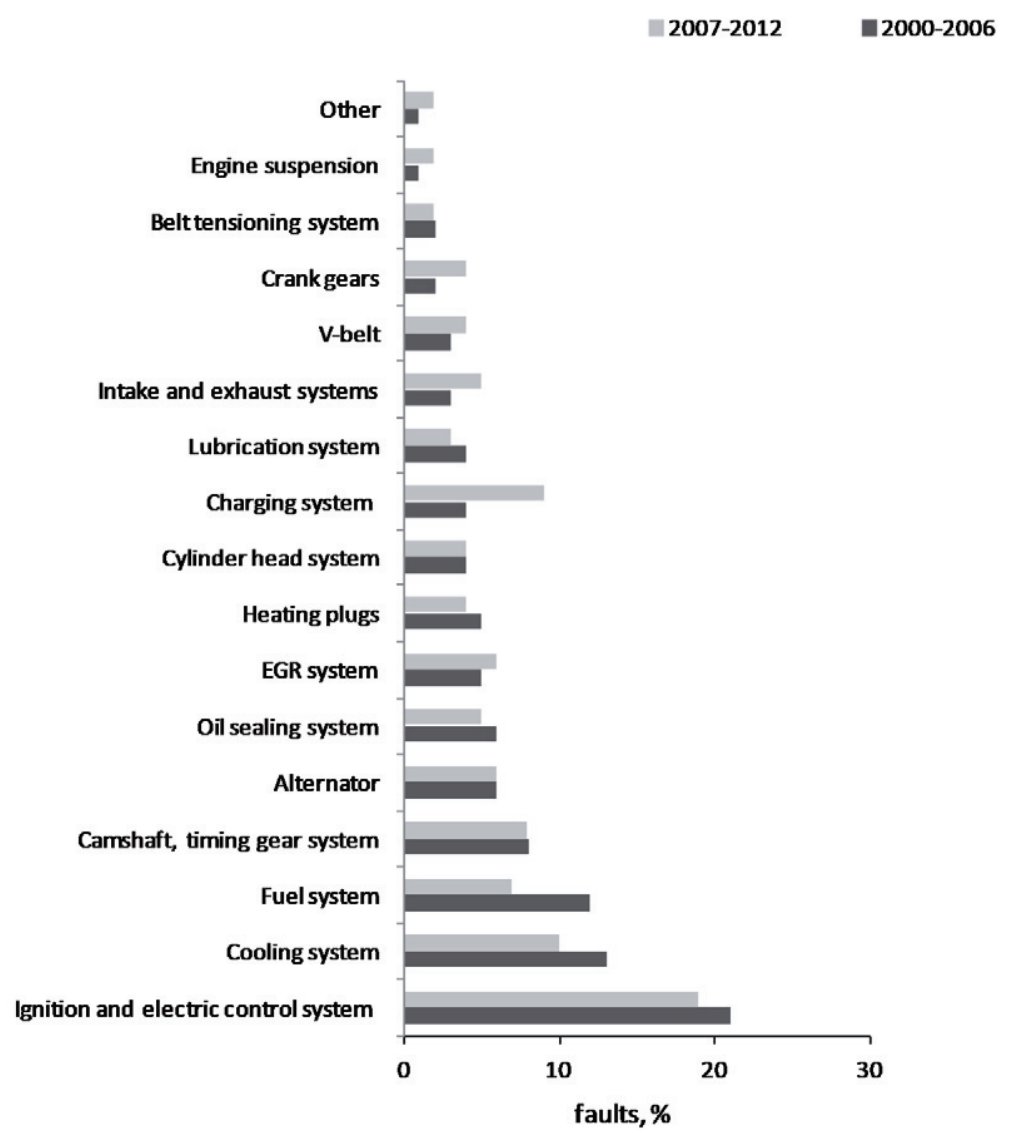

Fig. 3. Structure of engine faults [7]

Poorly made repair, material melting on the piston crown in diesel engines and piston fracture due to mechanical contact between the piston crown and the cylinder head were the main causes in the examined broken-down engines. The operational causes of cylinder and piston damages which were recognized during the examinations can be classified as follows: over-fuelling of cylinder, exhaust restriction, improper injection timing, poor piston crown cooling, engine operation at excessive load. It is significant that the number of assembly errors, being the cause of piston faults in working engines, was relatively small.

An important group of engine failures has been related to damages of the turbocharging systems. The types of faults of engines, which were connected with turbocharging system, can be classified as follows: low power of engine, oil leakage, abnormal turbocharger noise, damages of 
wastegates, damages of pneumatic control system in VTG turbochargers and electrical control system in VTG turbochargers, faults of engine control module and mechanical damages of a turbine and compressor. The causes of damages due to overheating include blocked air filter, shutting off the engine after work at high or medium load too soon, poor quality of engine oil, too long time between oil changing, not airtight inlet and exhaust manifold which are not airtight, faulty injectors, faulty lubrication system of the turbocharger, defective drainage oil system (crankcase ventilation defects).

The causes of damages from exceeding from the rotation speed limit include increasing the engine power by changing the control parameters and overloading of the turbocharger.

The main symptoms of turbocharger damages include poor co-operation between the charging system and the engine control unit system, too low boost pressure at low engine speeds and significant deterioration in its performance as well as the increase of toxic exhaust emissions, incorrect fuel mixture, the combustion temperature increase, which can damage the turbocharger and the engine, too high boost pressure which results in exceeding the rotation speed of a turbine and the risk of mechanical damage (cracks) of a rotor, fast (in extreme cases sudden) increase of boost pressure, which can damage piston-crack system or engine timing system, noisy work of turbochargers, usually accompanied by the accelerated wear, considerably increased toxicity of exhaust gases, which eliminates the vehicle from being used.

Durability of the engine can be defined as the ability to maintain the normative values of the significant operating properties (for example the right boost pressure, vibration), during the total operating time. Increasing the mechanical and thermal forcing reduces the durability of engine. Obtaining the required level of durability is possible by using engine components made of materials with significantly increase the resistance to mechanical and thermal load.

Reliability of engine is related to the design and the production quality, operating conditions (e.g. oil condition, oil supply) and the system of technical service. The results of examination of faulty engines have shown that $26 \%$ of faults were connected with operating conditions and quality of service. For turbocharged engines $5 \%$ of faults were connected with engine lubrication system. The results of previous studies [7] have shown that the turbocharged engines were much more sensitive to malfunction of lubrication system compared to naturally aspirated engines. Likelihood of turbocharger damages as a result of faults which had been connected with engine lubrication system, increased with the mileage of a car. The main causes of engine faults during the initial period of operation (below eighty thousand kilometres) have been connected with control system and improper operation.

Faulty injection system, poor service, assembly errors during a repair, overheating as a result of overloading or faulty cooling system were the most common causes of total engine failure.

The most common errors made during repairs have been classified as follows: improper assembly of engine parts, insufficient clearances between particular parts, improper handling of engine parts during installation, inaccurate measurements before installation (e.g. cylinder axis not perpendicular to crank shaft axis), insufficient cleanness in the process of repair.

Poor maintenance results in bad lubrication or even no lubrication at all, inadequate circulation of the coolant, excessive water in fuel, etc.

\section{Fault detection}

Four methods of diagnosing have been used in order to locate the engine faults and to define the type of faults: the use of the OBD system, measurements of electrical values, organoleptic methods including endoscopy and examining the engine during dynamometer stand tests.

Fifty six percent of faults were not detected during a single test. Damages of turbochargers were the most difficult ones to diagnose. Early detection of piston and cylinder damages was only possible applying endoscopy. Fault of fuel injection has not been detected using OBD system examinations in any case. It was recognized only through the endoscopy examination, as the cause 
of piston crown erosion at the early phase. It is very important because there was a large number of cases of completely broken-down engine, due to faulty injection systems in diesel engines. Percentage of false conclusions concerning particular diagnosing tests has been presented in Fig. 4.

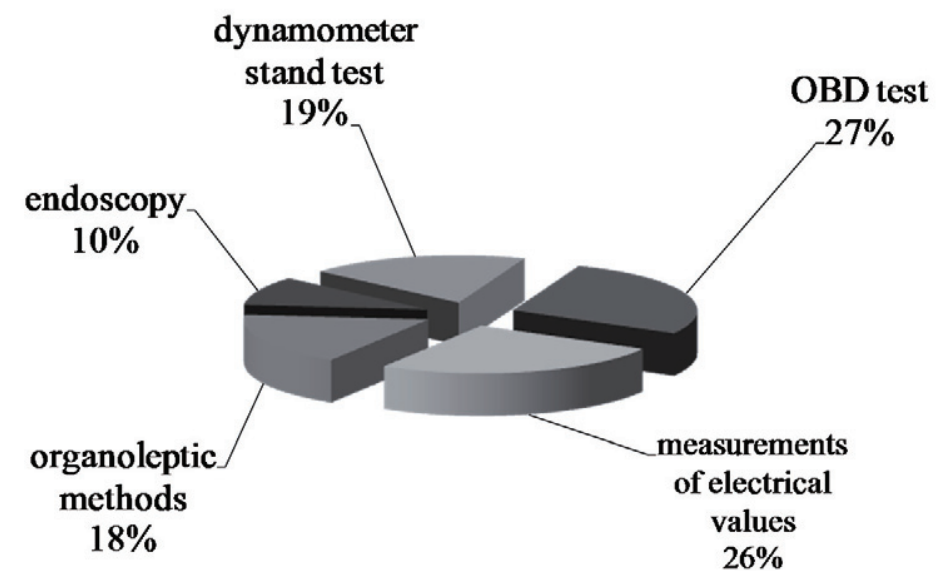

Fig. 4. Percentage of false conclusion concerning single diagnosing test

The application of commonly used design of internal combustion engines control systems and the development of measuring methods allow working out new ways of engine performance control.

These problems in real time are the subject of many research works regarding control and monitoring of the changes, which tune the engine parameters depending on the outside conditions and circumstances. The air follow control through the intake system, engine load, air parameters and control unit (feedback) have a considerable impact on the process of cylinder filling and the quality of mixture at the moment of ignition. The feedback depends on momentary engine work parameters such as the cooling temperature, oil temperature, temperature and mass flow and vibration of engine block caused by knock combustion.

Exhaust gas emission, which is of residual nature in a combustion process, is at the same time an important source of information about combustion process itself. The course of combustion process is directly related to the condition of mixture in the cylinder and the moment of ignition. Both the conditions of mixture (the air mass ratio) and the moment of ignition are controlled taking into account feedback signals which has characterize engine performance in previous work cycles. It can thus be assumed that particular groups of values of control parameters in feedback system, certain groups of emission level of pollutants can be assigned. The on-line diagnostics systems can help to avoid costly engine repairs by identifying maintenance and repair needs early enough and to reduce the repair time by indicating the fault location.

\section{Conclusion}

The causes of engine faults can be classified as follows: those ones due to normal wear during operation, maintenance errors, damages of lubrication and cooling systems, faults of injection and timing systems, manufacturing defects. A high percentage of faulty engines with low mileage shows that early diagnosis of damages is extremely important. The faults of electronic control system, ignition timing and engine management malfunction may be the reason of a complete destruction of the engine. Single method of diagnosis may not be sufficient to detect certain types of failures. It is important to keep in mind that a lot of engine damages can be caused by many different types of faults. Therefore, finding the cause of engine damages can be sometimes extremely difficult. The development of diagnostic methods of engines is much slower than the progress in the area of new engine construction and new fault associated with this. 
The so far carried out examinations have revealed that some mechanical damages of engines such as operating wear or unexpected faults do not make the diagnosing system react. This can be a result of algorithms of adaptation of engine control system which compensate the impact of faults. The use of several diagnostic tests increases the probability of detecting a fault at an early stage. The engine condition tests should be carried out before the onset of the first symptoms of failure.

\section{References}

[1] Filipczyk, J., Madej, H., The typical faults of automotive engines and analysis for fault diagnosis possibility, Combustion Engines, 2009-SC2, pp. 229-233.

[2] Filipczyk, J., Madej, H., The application of on-board diagnostics systems for assessing the technical state of automotive vehicles, Journal of KONES Powertrain and Transport, Vol. 17, No. 3, pp. 99-104, 2010.

[3] Silva, F. S., Fatigue on engine pistons - A compendium of case studies, Engineering Failure Analysis 13, pp. 480-492, 2006.

[4] Waldhauer, U., Schiling, U., Schnaibel, S., Szopa, J., MSI Motor Sevice International, PartNo. 50003 973-02.

[5] Jimenez Espadafor, F., Becerra Villanueva, J., Torres Garcia, M., Carvajal Trujillo E., Analysis of a diesel generator cylinder failure, Engineering Failure Analysis 18, pp. 913-925, 2010.

[6] Barelli, L., Bidini, G., Bonucci, F., Diagnosis methodology for the turbocharger groups installed on a 1 MW internal combustion engine, Applied Energy 86, pp. 2721-2730, 2009.

[7] Filipczyk, J., Causes of automotive turbocharger Faults, Transport Problems, Vol. 8, No. 2, 2013. 